\title{
Persistent increase in the incidence of STIs in MSM in Madrid
}

Oskar Ayerdi, Mar Vera, Teresa Puerta, Juan Ballesteros Petunia Clavo, Blanca Menéndez, Juan Carlos Carrió, Inmaculada Mozo, Natividad Jerez, Marta Ruiz, Sonsoles Del Corral, Mónica García, Montserrat Raposo, Carmen Rodríguez y Jorge Del Romero. Centro Sanitario Sandoval, IdISSC, Madrid.

\section{Background}

The loss of fear of AIDS caused by the high clinical and preventive efficacy of ART, the consumption of new recreational drugs and the easy finding sexual partners with social networks, has produced an increase in the STI incidence, especially among men who have sex with men (MSM). The objective was to evaluate the temporal evolution of syphilis, gonorrhea, chlamydiasis and lymphogranuloma venereum (LGV) incidence in MSM.

\section{Methods}

The study analyzed the period 2010-2016, in a STI clinic of Madrid. The $50 \%$ of the attended population were MSM. All patients diagnosed with syphilis, gonorrhea, chlamydiasis and LGV infection were included. All patients completed an epidemiological questionnaire to know its sociodemographic, clinical and behavioral characteristics.

\section{Results}

A total of 12,471 STI episodes were diagnosed: 3,784 syphilis (1 ${ }^{\mathrm{a}}, 2^{\mathrm{a}}$ and latent), 4,470 gonorrhea and 4,217 chlamydiasis.

\begin{tabular}{|l|c|c|c|}
\hline \multicolumn{1}{|c|}{ STI } & Total number of STls & Total number among MSM & \% among MSM \\
\hline Gonorrhea & 4,470 & 3,763 & $84.2 \%$ \\
\hline Syphilis (1로 \& $2^{\text {a }}$ ) & 1,389 & 1,299 & $93.5 \%$ \\
\hline Chlamydia (D-K) & 3,667 & 1,932 & $52.7 \%$ \\
\hline LGV & 550 & 500 & $91 \%$ \\
\hline
\end{tabular}

Regarding the temporal evolution of the STI incidence in MSM during the period analyzed, we have found a persistent increase going from 716 cases in 2010 to 1,672 in 2016 , which corresponds to a $133 \%$ increase.

\begin{tabular}{|c|c|c|c|c|c|c|c|c|}
\hline STI & 2010 & 2011 & 2012 & 2013 & 2014 & 2015 & 2016 & Total \\
\hline Gonorrhea & 279 & 262 & 297 & 463 & 759 & 815 & 888 & 3,763 \\
\hline Syphilis $\left(1^{a} \& 2^{a}\right)$ & 174 & 161 & 160 & 145 & 161 & 203 & 295 & 1,299 \\
\hline Chlamydia (D-K) & 236 & 221 & 266 & 220 & 340 & 295 & 354 & 1,932 \\
\hline LGV & 27 & 57 & 49 & 76 & 88 & 68 & 135 & 500 \\
\hline Total & 716 & 701 & 772 & 904 & 1,348 & 1,381 & 1,672 & 7,494 \\
\hline
\end{tabular}

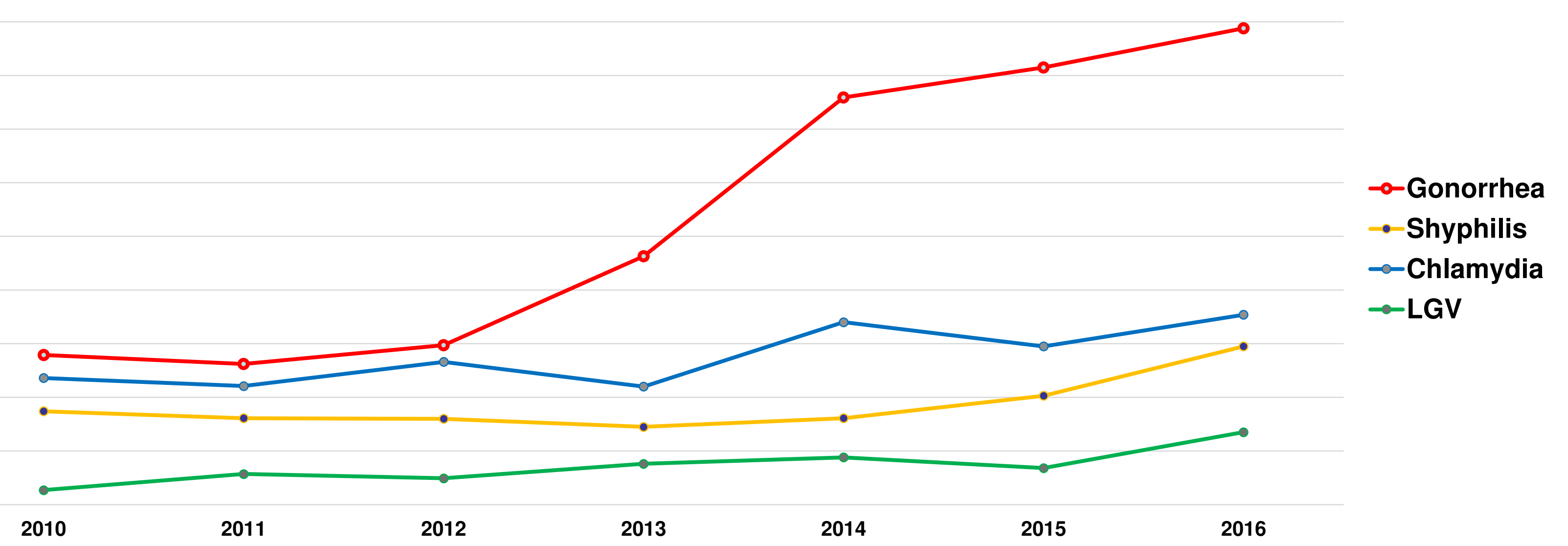

